\title{
IN MEMORIAM BORIS TERK
}

Boris Terk a été l'un des plus fidèles compagnons de la Revue d'ODF depuis sa création. Il a été pendant plusieurs années membre du bureau de l'Association de la Revue.

Sa présence active aux réunions, ses interventions pertinentes où il montrait à la fois des convictions fermes et une grande ouverture d'esprit, accompagnaient une exigence permanente de perfectionnement. Sa participation assidue aux conférences et aux cours dispensés par R.M. Ricketts et C.F. Gugino, par exemple, en témoigne.

Homme de cœur et d'esprit, il possédait de plus une culture littéraire et musicale l'ayant conduit à l'écriture, avec : « De l'incision » (éd. URDLA), texte imaginé à partir des planches de dissection fascinantes de J.F. Gautier d'Agoty et « A voice is a person » (éd. Allia), regard admiratif sur la contralto Kathleen Ferrier.

La Revue adresse à son épouse et à sa famille, l'expression de ses condoléances, de sa tristesse et de sa sympathie.

La Revue 